\title{
Study on Carbon Nanocomposite Counterelectrode for Dye-Sensitized Solar Cells
}

\author{
Yiming Chen, Haiyan Zhang, Yuting Chen, and Jiapeng Lin \\ Faculty of Material and Enemy, Guangdong University of Technology, Guangzhou 510006, China \\ Correspondence should be addressed to Yiming Chen, chenym@gdut.edu.cn
}

Received 22 October 2011; Accepted 23 March 2012

Academic Editor: Teng Li

Copyright () 2012 Yiming Chen et al. This is an open access article distributed under the Creative Commons Attribution License, which permits unrestricted use, distribution, and reproduction in any medium, provided the original work is properly cited.

Carbon nanocomposite electrodes were prepared by adding carbon nanotubes (CNTs) into carbon black as counterelectrodes of dye-sensitized solar cells(DSSCs). The morphology and structure of carbon nanocomposite electrodes were studied by scanning electron microscopy. The influence of CNTs on the electrochemical performance of carbon nanocomposite electrodes is investigated by cyclic voltammetry and electrochemical impedance spectroscopy. Carbon nano composite electrodes with CNTs exhibit a highly interconnected network structure with high electrical conductivity and good catalytic activity. The influence of different CNTs content in carbon nanocomposite electrodes on the open-circuit voltage, short-circuit current, and filling factor of DSSCs is also investigated. DSSCs with 10\% CNTs content exhibit the best photovoltaic performance in our experiments.

\section{Introduction}

Since the technological breakthrough of dye-sensitive solar cells (DSSCs) in 1991, a great deal of progress has been made in various aspects ranged from main critical materials constituting DSSCs to the related manufacturing technologies, which covers both fundamental studies on DSSCs with small area and large-scaled industry researches.

The current studies on DSSCs are mainly focused on dye synthesis $[1,2]$, electron transfer kinetics [3], photoanode [4-7], solid (or quasi-solid) electrolyte [8-10], and so forth, while the specific researches on counterelectrodes (CEs) are relatively rare. As a important part of dye-sensitive solar cell, counterelectrode usually consists of conductive glass loaded with platinum or carbon as catalysts, which can enhance the charge transfer between the CE and electrolyte interface, decrease the recombination possibility of $\mathrm{I}_{3}{ }^{-}$and the electrons in the conduction band of $\mathrm{TiO}_{2}$, restrain the dark current, and consequently improve the open circuit voltage $\left(V_{\text {oc }}\right)[11,12]$. So far, the platinum (or other precious metals) CEs have superior performance and thoroughly theoretical research, but they cannot be applied in large due to their high cost. Carbon, one low cost but high efficient catalyst $[13,14]$, can be used in CEs, and after high temperature treatment, the photoelectric properties of carbon CEs approach those of platinum CEs. Carbon and its mixtures can contact well with the substrate at low temperature, which facilitates the manufacture of large-scaled electrodes, thus having a promising application prospect.

Ramasamy et al. [15] used spray-coated multiwall carbon nanotubes (CNTs) film on fluorine-doped tin oxide glass as CEs, and got a maximum energy conversion efficiency of $7.59 \%$ under one sun illumination $\left(100 \mathrm{~m} \mathrm{~W} \mathrm{~cm}^{-2}\right.$, AM1.5G). Furthermore, electrochemical impedance spectroscopy analysis indicated a decrease in the charge transfer resistance of multiwall CNT CEs with increase of spraying time. Lee et al. [16, 17] made CEs for DSSCs by nanocarbon powder, which received a $7.56 \%$ photoelectric conversion efficiency, after 60 days of aging in dark room, the photoelectric conversion efficiency still remained $6.35 \%$ (i.e., $84 \%$ of its initial day efficiency $(\eta)$ ), with increases of opencircuit voltage $\left(V_{\mathrm{oc}}\right)$ and fill-factor $(\mathrm{FF})$ but a decrease of short-circuit current density $\left(J_{\mathrm{sc}}\right)$. Murakami et al. [18] fabricated carbon CEs by using carbon black, under AM1.5 illumination simulation achieving a photoelectric conversion efficiency $(\eta)$, short-circuit current density $\left(J_{\text {sc }}\right)$, open-circuit voltage $\left(V_{\mathrm{oc}}\right)$, and fill-factor $(\mathrm{FF})$ up to $9.1 \%, 16.8 \mathrm{~mA} / \mathrm{cm}^{2}$, $798 \mathrm{mV}$, and $68.5 \%$, respectively. As is well known that the fill-factor (FF) depends on the thickness of the carbon layer, 
when the thickness is less than $10 \mathrm{um}$, the photoelectric conversion efficiency $(\eta)$ improves as the thickness increases and the impedance decreases as the carbon layer thins. Huang et al. [19] manufactured CEs consisting of hard carbon spherules (HCSs), and the total photoelectric conversion efficiency $(\eta)$ was $5.7 \%$, while that of platinum CEs under the same circumstance was $6.5 \%$. Trancik et al. [20] believe that CNTs can provide accreted locations for reagents due to their microdefects and offer excellent catalystic effect when serving as CEs for DSSCs.

Nevertheless, at present researches on carbon nanocomposite CEs for DSSCs and the corresponding synergistic effect are rarely reported. In this paper, multiwall carbon nanotubes (MWCNTs) were added into nanocarbon black, and the related influence on the catalytic activity of carbon CEs were investigated as well.

\section{Experimental Procedure}

\subsection{Electrode Plate Fabrication}

2.1.1. Counterelectrode Fabrication. Carbon nanotubes (99.9\%, diameters: 40-60 nm, Shenzhen Nanotechnologies Co. Ltd, China) were added into nanocarbon black $(99.9 \%)$ with the mass fraction $30 \%, 15 \%, 10 \%, 5 \%, 0 \%$, and marked as sample A, B, C, D, and E, respectively. To enhance the dispersity of CNTs, a spot of emulsifying agent (Tianjin FuChen Chemistry Ltd., China) was added into above samples, and acetylacetone as pore-forming agent to enlarge the interface between electrode and electrolyte, with ethyl cellulose as adhesive. The mass ratio of CNTs, nanocarbon black, ethyl cellulose, emulsifying agent, and acetylacetone was x: 1: 0.125: 0.1: 0.1 (x altered from 0.3, 0.15, 0.1, 0.05 to 0 ), and appropriate amount of butanone was introduced as solvent. The mixture solutions were dispersed by ultrasonic cleaning to obtain homogeneous suspensions. Finally, a specific amount of the suspension was dropped onto the FTO glass, and then dried under room temperature for $1 \mathrm{~h}$. The CEs plates for DSSCs were prepared with the dimension $8 \mathrm{~mm} \times 8 \mathrm{~mm}$. Under the protection of nitrogen, the as-prepared electrode plates were heated at $450^{\circ} \mathrm{C}, 600^{\circ} \mathrm{C}$, $800^{\circ} \mathrm{C}$ for 30 minutes, respectively.

2.1.2. Photoanode Plate Fabrication. The mixture comprising of $3 \mathrm{~g}$ nano- $\mathrm{TiO}_{2}$ powder (Germany Degussa Ltd.), $10 \mathrm{~mL}$ ethanol together with $0.5 \mathrm{~mL}$ emulsifying agent and acetylacetone was ultrasonically dispersed to homogeneous $\mathrm{TiO}_{2}$ suspension of proper viscosity. A specific amount of the suspension was droped onto FTO glass, and then the FTO glass was dried under room temperature for $1 \mathrm{~h}$ and then heated at $450^{\circ} \mathrm{C}$ in atmosphere for 30 minutes. Once the as-obtained $\mathrm{TiO}_{2}$ plate was cooled, the $\mathrm{TiO}_{2}$ suspension was once again dropped onto it, and the same drying and heating as mentioned above were sequently conducted. After 3 or 4 time repetitions of the same procedure, $\mathrm{TiO}_{2}$ multilayer membrane electrode plates were obtained with the dimension of $8 \mathrm{~mm} \times 8 \mathrm{~mm}$, the same as that of the CE plate.

\subsection{Electrochemical Performance Testing}

2.2.1. Carbon Electrodes Catalytic Performance and Interface EIS Testing. The testing system consisted of nanocarbon electrode, platinum (PT) electrode, and electrolytic cell. The testing electrolyte was the mixture of $\mathrm{KI}$ and $\mathrm{I}_{2}\left(\left[\mathrm{I}^{-}\right]:\left[\mathrm{I}_{2}\right]=\right.$ $10: 1), 0.1 \mathrm{M} \mathrm{KCL}$ as supporting electrolyte. The mixed solution of $25 \%$ anhydrous alcohol and $75 \%$ deionized water was used to improve iodine solubility. PT electrode served as the cathode.

The electrochemical reaction process of this electrolytic cell is shown in the following equations:

$$
\begin{gathered}
\mathrm{I}_{3}{ }^{-}+2 \mathrm{e}^{-} \rightleftharpoons 3 \mathrm{I}^{-}, \\
3 \mathrm{I}_{2}+2 \mathrm{e}^{-} \rightleftharpoons 2 \mathrm{I}_{3}^{-}, \\
\mathrm{I}^{-}+\mathrm{I}_{2}=\mathrm{I}_{3}^{-} .
\end{gathered}
$$

The reaction mechanism is as follows: $\mathrm{I}_{3}{ }^{-}$and $\mathrm{I}_{2}$ are deoxidized near the cathode and oxidized near the anode. The reduction of $\mathrm{I}_{3}{ }^{-}$and $\mathrm{I}_{2}$ dominates the whole electrochemical process. The more active the electrode material is, the stronger the reduction of $\mathrm{I}_{3}{ }^{-}$and $\mathrm{I}_{2}$, and the better catalytic reduction performance for CEs is.

CHI660C electrochemical working station (Shanghai ChenHua instrument Ltd, China) was employed for C-V characteristic curve and EIS testing.

$\mathrm{C}-\mathrm{V}$ characteristic curve:measuring the reduction performance of CEs for $\mathrm{I}_{3}{ }^{-}, \mathrm{I}_{2}$ (such as reduction potential, reduction current density). Testing conditions: initial potential $1.5 \mathrm{~V}$, high potential $1.5 \mathrm{~V}$, low potential $0 \mathrm{~V}$, and scan rate $1-100 \mathrm{mV} / \mathrm{s}$.

EIS testing: $0.6 \mathrm{~V}$ initial potential was applied to simulate illumination for DSSCs and then test the interface impedance between the electrolyte and the carbon electrode. Testing conditions: initial potential $0.6 \mathrm{~V}$, high frequency $100000 \mathrm{~Hz}$, low frequency $1 \mathrm{~Hz}$, and amplitude $0.005 \mathrm{~V}$. The test data were fitted by ZView2 software.

2.2.2. DSSCs Photoelectric Properties and EIS Testing. A solar simulator (xenon lamp, AM1.5,100 $\mathrm{mW} / \mathrm{cm}^{2}$, calibrated by silicon standard solar cell, facular area $30 \mathrm{~cm} \times 30 \mathrm{~cm}$, intensity unhomogeneity less than 3\%), and Keithley 2400 Source Meter were performed, testing parameters of the cell, such as I-V characteristic curve, open-circuit voltage, shortcircuit current density. Testing conditions: initial potential $0 \mathrm{~V}$, high potential $0.8 \mathrm{~V}$, the quantity of measuring points 150.

EIS testing was employed by using CHI660C electrochemical working station, testing the complex impedance to obtain the CT impedance of CEs and electrolyte. Testing conditions: initial potential $0.6 \mathrm{~V}$, high frequency $100000 \mathrm{~Hz}$, low frequency $1 \mathrm{~Hz}$, amplitude $0.005 \mathrm{~V}$. The test data was fitted by ZView2 software. 


\section{Results and Discussion}

3.1. Surface Morphology Analysis of Electrodes. Scanning electron microscope (SEM, S-3400N) was employed to characterize the surface morphology of composite electrodes, and the SEM images of composite electrodes before and after thermal treatment were shown in Figures 1(a) and 1(b). It can be found in Figure 1(a) that, before thermal treatment, CNTs with the diameter $40-60 \mathrm{~nm}$ distributes near the carbon black, and the adhesive (ethyl cellulose) remains on the surface of carbon black, which decreases the contacting area between the carbon black and electrolyte, consequently affecting the corresponding catalytic performance. Figure 1(b) is the SEM image of composite electrode after $600^{\circ} \mathrm{C}$ thermal treatment under nitrogen atmosphere, indicating that the ethyl cellulose distributed between carbon black and CNTs surface decreases greatly. Furthermore, CNTs forms a network, to which carbon black evenly adheres, building a "grape cluster" structure and then getting a synergistic effect. After thermal treatment the outer diameters of CNTs decrease obviously. Due to high conductivity of CNT, electrons can conduct via the CNTs network distributed on the electrode film, which effectively enhances the conductivity of the electrodes. Moreover, the carbon black adhered to CNTs could enlarge the contacting area with the electrolyte, resulting in an increase of catalytic performance.

\subsection{Electrochemical Performance Testing Results}

3.2.1. Effects of CNTs Addition on the Reduction of $\mathrm{I}_{3}{ }^{-} / \mathrm{I}^{-}$. At the scan rate $1-100 \mathrm{mV} / \mathrm{s}$, the current density peak curves of PT CEs and CNTs-nanocarbon black composite CEs are shown in Figure 2. By the comparison of the reduction current peak of $\mathrm{I}_{3}{ }^{-}$and $\mathrm{I}_{2}$ at different scan rates, it is revealed that current densities are all approximately in direct ratio with the square root of scan rates, which indicates that the total reaction rate depends on the ion diffusion in the electrolyte rather than the reduction rate of the ions absorbed onto the electrode surface. Among the reactions taken place on the electrode surface, the required potential of $\mathrm{I}_{3}{ }^{-}+$ $2 \mathrm{e}^{-}=3 \mathrm{I}^{-}$is higher than that of $3 \mathrm{I}_{2}+2 \mathrm{e}^{-}=2 \mathrm{I}_{3}^{-}$, namely $\mathrm{I}_{3}{ }^{-}$is much more difficult to deoxidize than $\mathrm{I}_{2}$. However, the transmission (or diffusion) rate of electrons and ions within electrodes is less than the reduction rate of ions on the electrode surface, thus the diffusion of $\mathrm{I}_{3}{ }^{-}$is the determinant of CEs activity.

We can also find in Figure 2 that, at the same scan rate, composite carbon electrode with CNTs has a bigger reduction current density for $\mathrm{I}_{3}{ }^{-}$than that of PT electrode, on the other hand, the reduction current density for $I_{2}$ is smaller than that of PT electrode. The above results indicates that composite electrodes have stronger reduction for $\mathrm{I}_{3}{ }^{-}$ than PT electrodes, but when it comes to the reduction for $\mathrm{I}_{2}$, the situation is totally opposite.

Figure 3 reveals the curves of the electrochemical catalytic performance of CEs versus the adding amount of CNTs. CEs with CNTs adding weight of $30 \%, 15 \%, 10 \%$, $5 \%$, and $0 \%$ enable $\mathrm{I}_{2}$ with reduction potentials of -0.41 ,
$-0.44,-0.51,-0.57$, and $-0.59 \mathrm{~V}$ sequently, as well as the reduction current density 4.98, 5.37, 4.68, 4.41, and $2.78 \mathrm{~mA}$, respectively. Meanwhile, the corresponding parameters for $\mathrm{I}_{3}{ }^{-}$are similarly $-0.77,-0.83,-0.92,-0.96$ and $-0.92 \mathrm{~V}$ together with 5.82, 6.04, 5.31, 5.15, 3.44 mA.

It can be concluded that CEs with CNTs have obviously superior catalytic reduction ability to those without. And the catalytic reduction potentials of electrodes decrease after the addition of CNTs.

By adding specific amount of CNTs into counterelectrode, the catalytic performance of CEs is enhanced effectively; however, the enhancement is not direct ratio with the adding amount. We discover that the electrode performance of $15 \%$ CNTs adding is better than that of $5 \%$ and $10 \%$, nevertheless, when the adding amout reaching 30\%, its catalysis declines. Furthermore, once the mass fraction of CNTs in carbon black exceeds $30 \%$, the catalytic reduction potential of electrodes increases and the current density decreases.

\subsubsection{Effects of CNTs Addition on Carbon Electrode/Electrolyte} Interface Impedance. The electrochemical impedance spectroscopy of nanocarbon electrode at $28^{\circ} \mathrm{C}$ is displayed in Figure 4 , and the electrochemical impedance curves were fitted via the equivalent circuit in Figure 4. When conducting the fit, $W, R(\mathrm{E}), \mathrm{CPE}(\mathrm{E}), R_{S}$ were set as fixed value in the equivalent circuit model, where $R_{\mathrm{CT}}(\mathrm{C}), R(\mathrm{E}), W, R_{S}$ stand for the interface impedance between carbon electrode and electrolyte, PT electrode and electrolyte interface, Warburg impedance of electrolyte together with the contact impedance between $\mathrm{C}, \mathrm{TiO}_{2}$, and FTO. $R_{\mathrm{CT}}$ indicates the resistance caused by charge transfer on the electrode surface.

$\mathrm{CPE}$ reveals the double-layer capacitance of the interface, with the expression $Z_{\mathrm{CPE}}=T(j w)^{-P}(0 \leq P \leq 1)$. $Z_{\mathrm{CPE}}$ has two variables, that is, $T$ and $P$, to be exactly, $T$ revealing the solid-liquid interface capacitance, and $P$ displaying the surface roughness of the electrode, namely, the deviation from plate condenser, thus indicating the capacitance characteristics of CPE. $W$ characterizes the electrolyte impedance due to diffusion.

Table 1 shows that, the $R_{\mathrm{CT}}$ of carbon black-CNTs composite electrodes decreases obviously compared with nanocarbon black electrodes, that is, the resistance caused by charge transfer on the electrode surface decreases, due to the extraordinarily high conductivity and the netted CNTs being the bridges for electron transfer between carbon blacks. Moreover, there are some defects on the surface of CNTs, which can provide attachment position for reagent and accelerate the electron exchange between electrode and reagents. Nevertheless, the CPE-P of composite electrodes is less than that of carbon black, revealing the increase of surface roughness of electrodes after the adding of CNTs into carbon black, which may be caused by the diameter variance between CNTs and carbon black. The CPE-T of composite electrodes increases obviously, manifesting the increase of double-layer capacitance between the solid-liquid interface and the decrease of the interface 


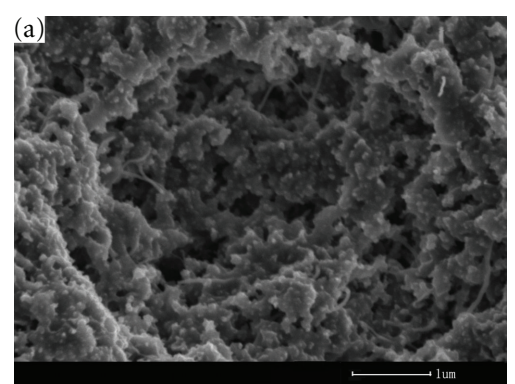

(a)

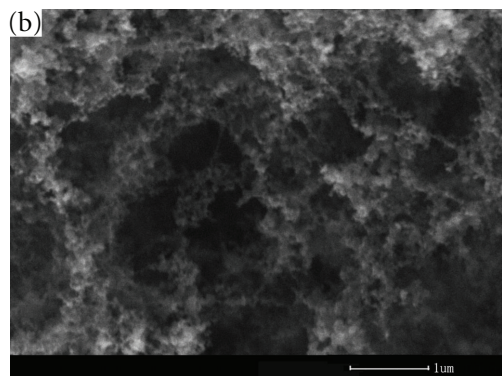

(b)

FIGURE 1: SEM image of the composite electrode: (a) untreated composite electrode-(b) composite electrode treated at $600^{\circ} \mathrm{C}$ in nitrogen.

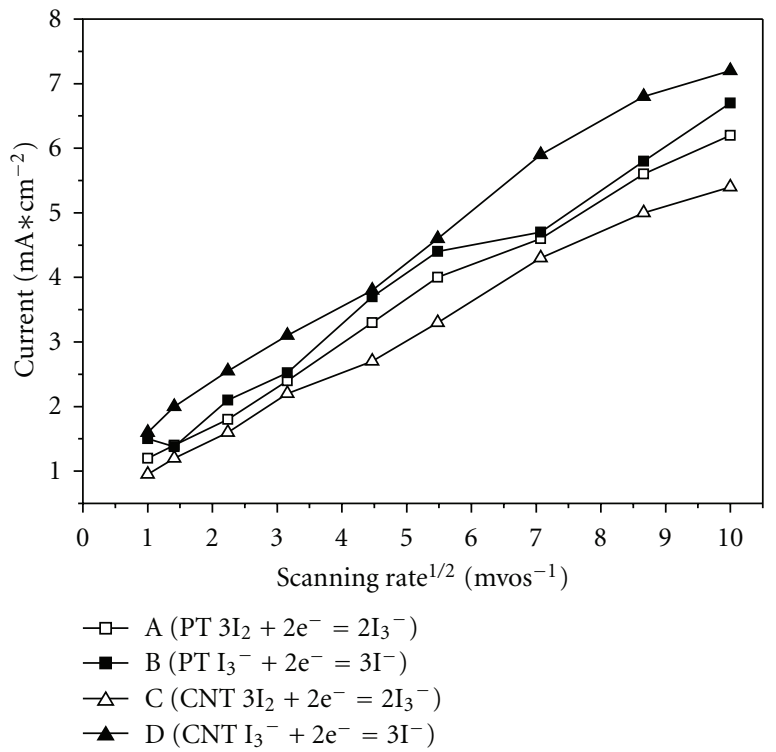

Figure 2: Peak current of cyclic voltammograms on composite electrode and Pt electrode.

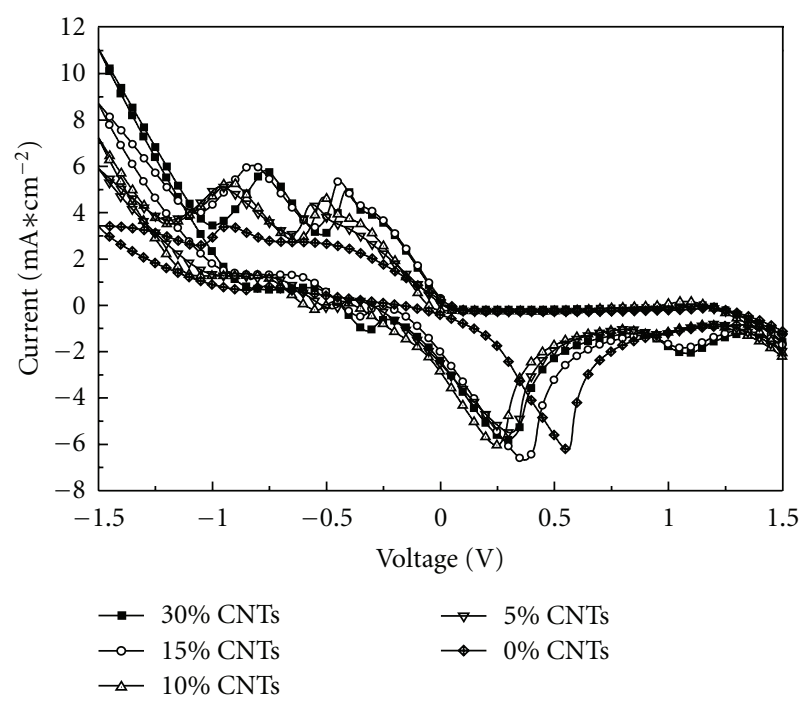

FIGURE 3: Cyclic voltammograms for composite electrode with different CNTs additions.

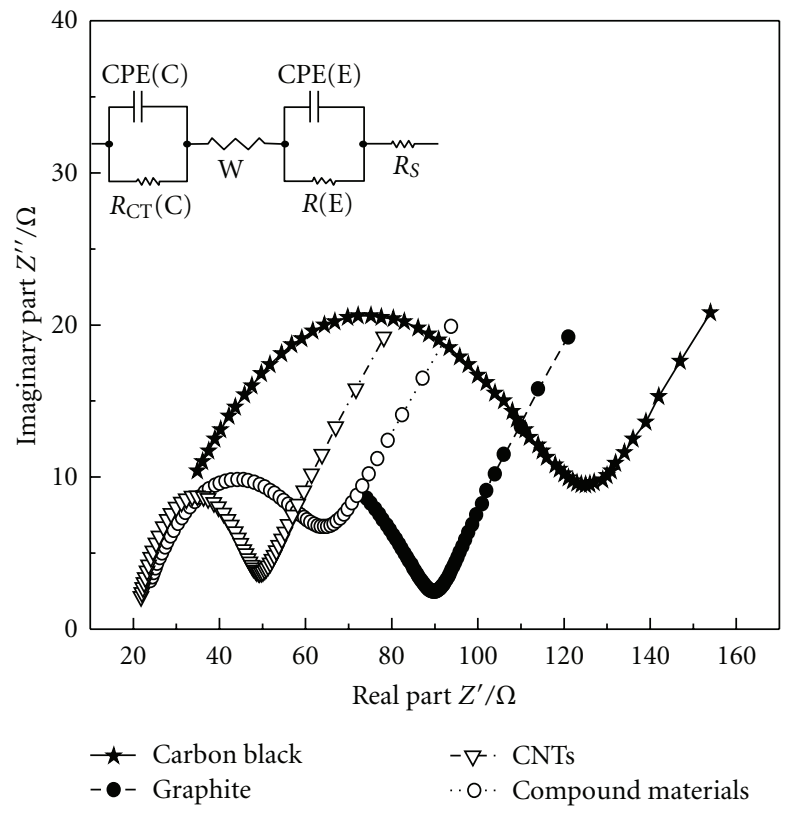

FIGURE 4: Electrochemical impedance spectroscopy and its equivalent circuit of nanocarbon electrode.

electric potential difference between the electrode and electrolyte.

3.2.3. Effects of CNTs Addition on the Impedance of DSSCs. The electrochemical impedance spectroscopy for DSSCs with different CNTs additions at $30^{\circ} \mathrm{C}$ is shown in Figure 5, and was fitted by the equivalent circuit insetted in Figure 5, where $R_{\mathrm{CT}}\left(\mathrm{TiO}_{2}\right)$ and $\mathrm{CPE}\left(\mathrm{TiO}_{2}\right)$ represent the interface impedance between $\mathrm{TiO}_{2}$ electrode and electrolyte. It is shown in Table 2 that, as the CNTs addition rises, the CPE-P decreases, leading to increases of both the surface roughness and the active catalytic points of the electrode surface; furthermore, the CPE-T decreases, resulting in the rise of the interface capacitance between the carbon electrode and electrolyte and the diminution of the electric potential difference of the two interfaces. Therefore, the catalytic performance of the CE is improved totally, which can be proved, in Figure 6, by all the increases of open-circuit voltage, short-circuit current, and the fill-factor for DCSs as 
TABLE 1: Fitting results for electrochemical impedance spectroscopy of nanocarbon electrode.

\begin{tabular}{lccc}
\hline Electrode material & $R_{\mathrm{CT}}(\mathrm{C}) / \Omega$ & CPE-T & CPE-P \\
\hline$\Phi 40-60$ nm CNT & 26.70 & $3.2462 E-5$ & 0.708 \\
Nanocarbon black & 104.3 & $9.6948 E-5$ & 0.568 \\
Graphite scale & 69.53 & $2.0033 E-5$ & 0.411 \\
Composite electrode & 43.04 & $2.1908 E-4$ & 0.512 \\
\hline
\end{tabular}

TABLE 2: Fitting results for electrochemical impedance spectroscopy for DSSCs with different CNTs addition.

\begin{tabular}{lcccc}
\hline CNTs content & $R_{\mathrm{CT}}(\mathrm{C}) / \Omega$ & CPE-T & CPE-P & $R^{S}$ \\
\hline $0 \%$ & 356.4 & $2.42 E-5$ & 0.922 & 65.1 \\
$5 \%$ & 1125.0 & $9.09 E-5$ & 0.718 & 121.4 \\
$10 \%$ & 194.4 & $3.39 E-4$ & 0.624 & 152.3 \\
$30 \%$ & 198.4 & $4.78 E-4$ & 0.573 & 242.3 \\
\hline
\end{tabular}

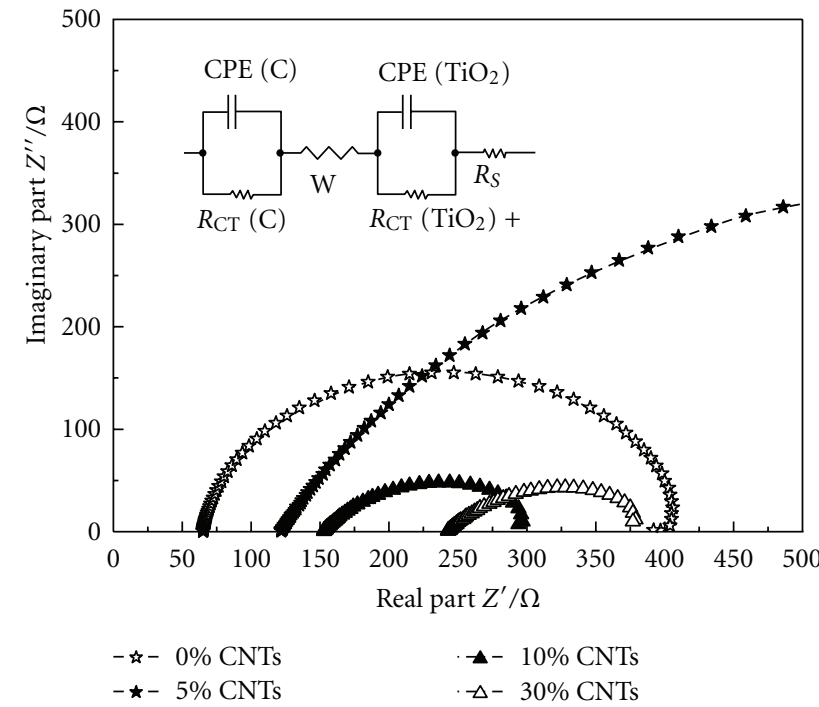

FIGURE 5: Electrochemical impedance spectroscopy for DSSCs and its equivalent circuit with different CNTs addition.

the rise of CNTs addition. However, as the increase of CNTs addition, $R_{S}$ has a certain rise, indicating the increasing of the surface resistance between carbon film and FTO glass.

3.2.4. Effects of CNTs Addition on the Photovoltaic Performance of DSSCs. Photocurrent-photovoltage characteristics of DSSCs with different CNTs contents are shown in Figure 6. Combined with Table 2 , it can be concluded that adding CNTs can improve the open-circuit voltage and short-circuit current of DSSCs. When the addition is less than $10 \%$, the open-circuit voltage, short-circuit current, and fill-factor increase as the CNTs contents rises, nevertheless, when the adding amount reaches $30 \%$, all the parameters mentioned above begin to reduce. The reason may be that with much CNTs addition, CNTs cannot be perfectly dispersed in carbon black and aggregate, resulting in the reduction of the

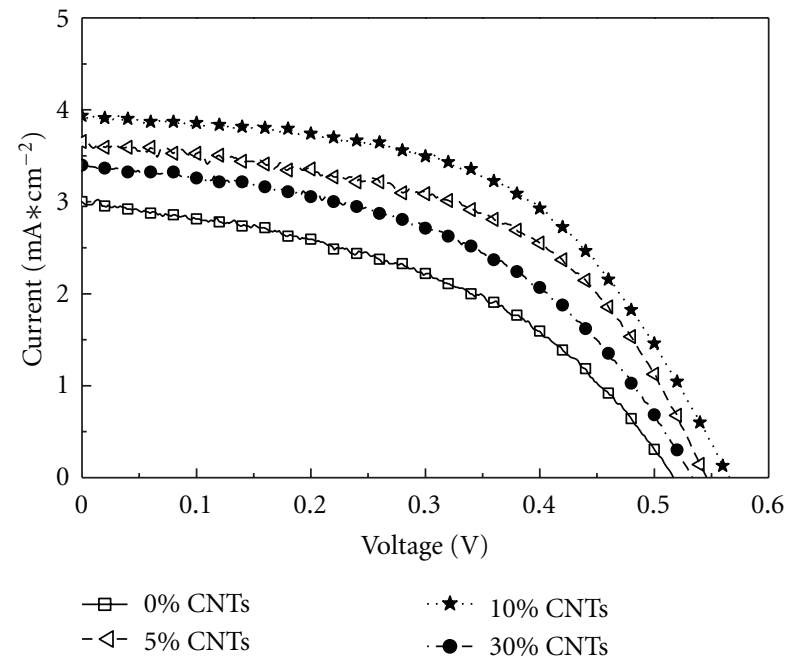

FIGURE 6: Photocurrent-photovoltage characteristics of DSSCs with different CNTs additions.

electrode surface area, and the increase of resistance caused by the charge transfer on the electrode surface.

\section{Conclusion}

CNTs with different content were added into nanocarbon counterelectrodes of DSSCs, and the effects of CNTs addition on the $\mathrm{I}^{-}$and $\mathrm{I}_{3}{ }^{-}$oxidation reduction in the electrolyte as well as the carbon electrode/electrolyte interface were investigated by cyclic voltammetry and electrochemical impedance spectroscopy. DSSCs were assembled to test the parameters of photovoltaic performance. The results indicated that carbon nanocomposite electrodes with CNTs adding exhibit a highly interconnected network structure with high electrical conductivity and good catalytic activity. When the content of CNTs is $15 \%$, the highest catalytic reduction ability of the electrode is obtained. With the CNTs 
adding, the interface capacitance between carbon electrode and electrolyte improves but the electric potential difference of the interface decreases.

\section{Acknowledgments}

This work is supported by the National Natural Science Foundation of China (no. 20971027), by National Science and Technology Support Project of China (no. 2012BAK26B00), by the Specialized Research Fund for the Doctoral Program of Higher Education of China (no. 20094420110005), by the Guangdong Provincial Natural Science Foundation of China (no. 9251009001000006), and by the Science and Technology Program of Guangdong Province of China (no. 2009A030301008, no. 2009B090300017, no. 2010A090200063, no. 2010498E21, no. 2010A011300041, no. 2011B050300017, 2011A090200084).

\section{References}

[1] C. Winder, G. Matt, J. C. Hummelen, R. A. J. Janssen, N. S. Sariciftci, and C. J. Brabec, "Sensitization of low bandgap polymer bulk heterojunction solar cells," Thin Solid Films, vol. 403-404, pp. 373-379, 2002.

[2] G. Calogero and G. D. Marco, "Red Sicilian orange and purple eggplant fruits as natural sensitizers for dye-sensitized solar cells," Solar Energy Materials and Solar Cells, vol. 92, no. 11, pp. 1341-1346, 2008.

[3] K. Tennakone, P. K. M. Bandaranayake, P. V. V. Jayaweera, A. Konno, and G. R. R. A. Kumara, "Dye-sensitized composite semiconductor nanostructures," Physica E, vol. 14, no. 1-2, pp. 190-196, 2002.

[4] M. Gratzel, "Sol-Gel processed $\mathrm{TiO}_{2}$ films for photovoltaic applications," Journal of Sol-Gel Science and Technology, vol. 22, no. 1-2, pp. 7-13, 2001.

[5] A. F. Nogueira and M. A. De Paoli, "Dye sensitized $\mathrm{TiO}_{2}$ photovoltaic cell constructed with an elastomeric electrolyte," Solar Energy Materials and Solar Cells, vol. 61, no. 2, pp. 135$141,2000$.

[6] W. J. Lee, E. Ramasamy, D. Y. Lee, and J. S. Song, "Glass frit overcoated silver grid lines for nano-crystalline dye sensitized solar cells," Journal of Photochemistry and Photobiology A, vol. 183, no. 1-2, pp. 133-137, 2006.

[7] S. Rani, P. Suri, P. K. Shishodia, and R. M. Mehra, "Synthesis of nanocrystalline $\mathrm{ZnO}$ powder via sol-gel route for dyesensitized solar cells," Solar Energy Materials and Solar Cells, vol. 92, no. 12, pp. 1639-1645, 2008.

[8] W. Geens, J. Poortmans, S. C. Jain et al., "Analytical study of PPV-oligomer- and C60-based devices for optimizing organic solar cells," Solar Energy Materials and Solar Cells, vol. 61, no. 1, pp. 43-51, 2000.

[9] S. Ganesan, B. Muthuraaman, V. Mathew, J. Madhavan, P. Maruthamuthu, and S. Austin Suthanthiraraj, "Performance of a new polymer electrolyte incorporated with diphenylamine in nanocrystalline dye-sensitized solar cell," Solar Energy Materials and Solar Cells, vol. 92, no. 12, pp. 1718-1722, 2008.

[10] C.-W. Shi, Q. Ge, B. Li, L. Tao, and Q. A. Liu, "Influence of additives on the performance of electrolytes in dye-sensitized solar cells," Acta Physico, Chimica Sinica, vol. 24, no. 12, pp. 2327-2330, 2008 (Chinese).

[11] K. Takahashi, N. Kuraya, T. Yamaguchi, T. Komura, and K. Murata, "Three-layer organic solar cell with high-power conversion efficiency of 3.5\%," Solar Energy Materials and Solar Cells, vol. 61, no. 4, pp. 403-416, 2000.

[12] K. Imoto, K. Takahashi, T. Yamaguchi, T. Komura, J. I. Nakamura, and K. Murata, "High-performance carbon counter electrode for dye-sensitized solar cells," Solar Energy Materials and Solar Cells, vol. 79, no. 4, pp. 459-469, 2003.

[13] T. Chen, Z. Sun, P. Guo, L. Wang, and S. Huang, "Deposition of carbon nanotubes film by LPCVD and related field emission property," Acta Optica Sinica, vol. 26, no. 5, pp. 777-782, 2006.

[14] Q. Zhu, H. Zhang, Y. Chen, Y. Chen, L. Chen, and D. Yang, "Synthesis of aligned carbon nanotubes film by plasmaenhanced hot filament chemical vapor deposition," Acta Optica Sinica, vol. 28, no. 9, pp. 1824-1827, 2008.

[15] E. Ramasamy, W. J. Lee, D. Y. Lee, and J. S. Song, "Spray coated multi-wall carbon nanotube counter electrode for tri-iodide $\left(\mathrm{I}_{3}^{-}\right)$reduction in dye-sensitized solar cells," Electrochemistry Communications, vol. 10, no. 7, pp. 1087-1089, 2008.

[16] W. J. Lee, E. Ramasamy, D. Y. Lee, and J. S. Song, "Performance variation of carbon counter electrode based dye-sensitized solar cell," Solar Energy Materials and Solar Cells, vol. 92, no. 7, pp. 814-818, 2008.

[17] W. J. Lee, E. Ramasamy, D. Y. Lee, and J. S. Song, "Grid type dye-sensitized solar cell module with carbon counter electrode," Journal of Photochemistry and Photobiology A, vol. 194, no. 1, pp. 27-30, 2008.

[18] T. N. Murakami, S. Ito, Q. Wang et al., "Highly efficient dye-sensitized solar cells based on carbon black counter electrodes," Journal of the Electrochemical Society, vol. 153, no. 12, Article ID 047612JES, pp. A2255-A2261, 2006.

[19] Z. Huang, X. Liu, K. Li et al., "Application of carbon materials as counter electrodes of dye-sensitized solar cells," Electrochemistry Communications, vol. 9, no. 4, pp. 596-598, 2007.

[20] J. E. Trancik, S. C. Barton, and J. Hone, "Transparent and catalytic carbon nanotube films," Nano Letters, vol. 8, no. 4, pp. 982-987, 2008. 

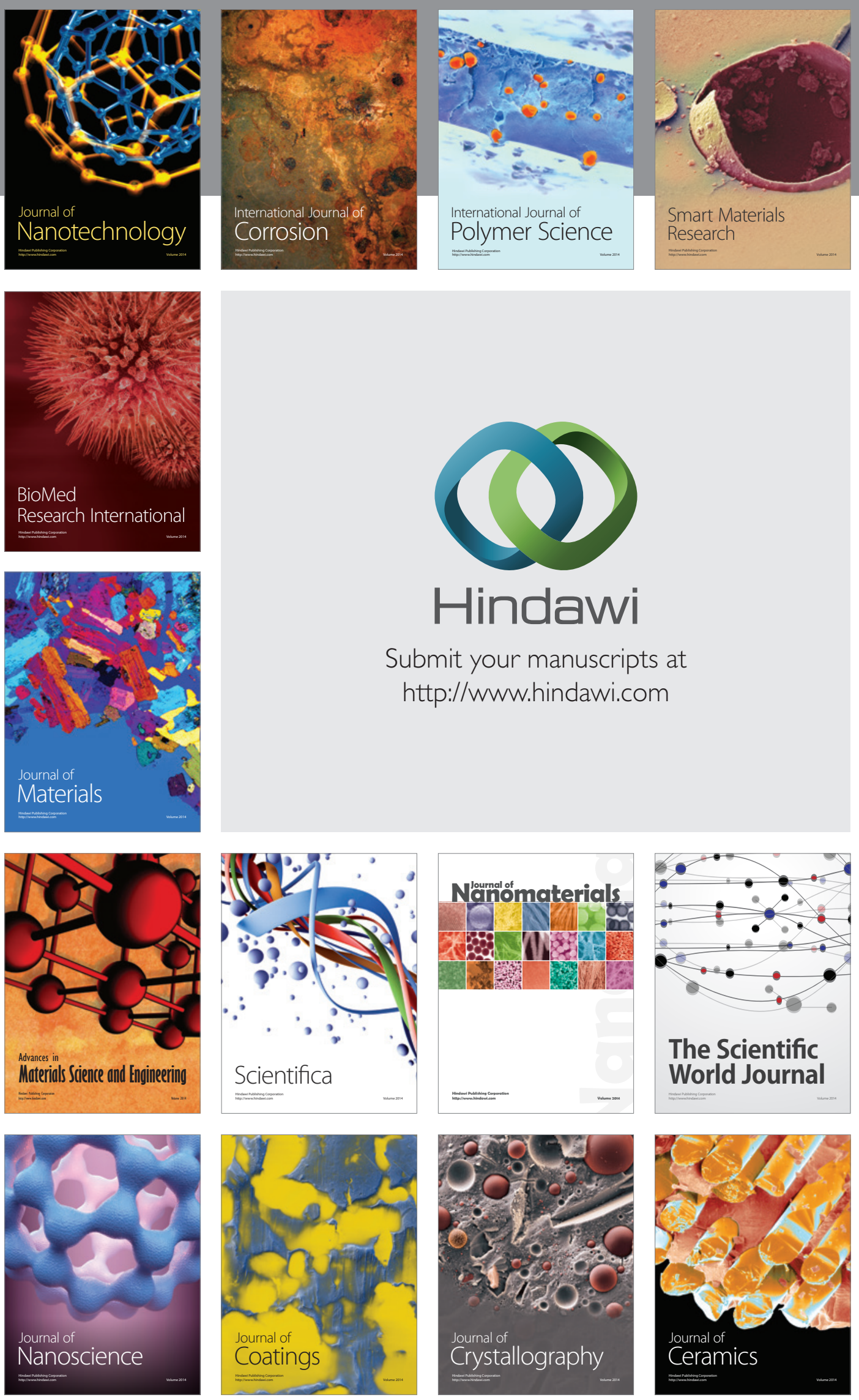

The Scientific World Journal

Submit your manuscripts at

http://www.hindawi.com

\section{World Journal}

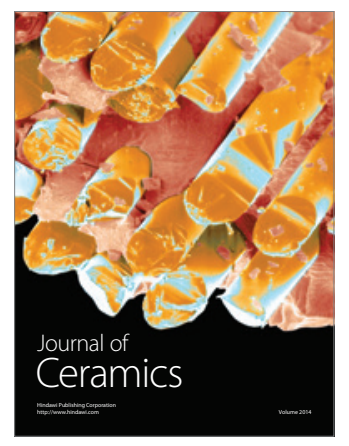

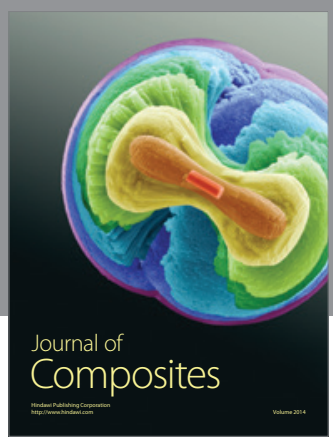
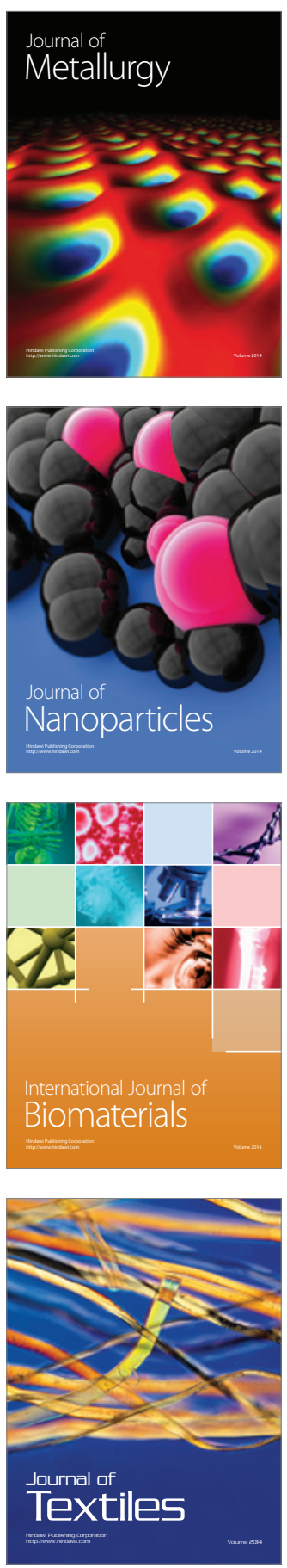